\title{
A Conversation Between Joanna Fowler and Johannes Czernin
}

\author{
Joanna S. Fowler ${ }^{1}$ and Johannes Czernin ${ }^{2}$ \\ ${ }^{I}$ Brookhaven National Laboratory, Upton, New York; and ${ }^{2}$ David Geffen School of Medicine at UCLA, Los Angeles, California
}

$\mathbf{J}$ ohannes Czernin, editor in chief of The Journal of Nuclear Medicine, earlier this year initiated a series of recorded discussions with leaders in nuclear medicine and molecular imaging. For this issue, he talked with Joanna Fowler, $\mathrm{PhD}$, senior chemist emeritus of the Department of Energy (DOE) Brookhaven National Laboratory (BNL; Upton, NY). Dr. Fowler also serves as a special volunteer at the National Institutes of Health (NIH); emeritus professor in the Department of Chemistry, Stony Brook University (NY); and adjunct professor in the Psychiatry Department, Mount Sinai School of Medicine (New York, NY).

Beginning in the 1970s, together with other researchers at BNL and academic centers, Dr. Fowler was a key figure in the development of ${ }^{18} \mathrm{~F}$-FDG to measure brain glucose metabolism. Her research interests center on radiotracer chemistry, focusing on using PET to image drug pharmacokinetics in the brain. Her early studies included imaging the uptake and movement of cocaine in the human brain, illuminating understanding of the reinforcing and addictive power of the drug. Her research was key in discovering that smokers have reduced levels of monoamine oxidase (MAO). Her most recent work focused on developing methods to understand the relationships among genes, brain chemistry, and behavior and on using PET to facilitate the identification and introduction of new drugs.

Fowler received her $\mathrm{PhD}$ in chemistry from the University of Colorado (Boulder) and did her postdoctoral work at the University of East Anglia (Norwich, U.K.) and at BNL. The year 2019 marks the 50th anniversary of her association with BNL, although she formally retired in 2014. She has published more than 500 peer-reviewed articles and has received numerous awards, including the Paul Aebersold Award and the Georg Charles de Hevesy Award from SNMMI (1997 and 2017, respectively); the E. O. Lawrence Award in Life Sciences from the DOE (1999); and the Garvan-Olin Award and the Glen T. Seaborg Award from the American Chemical Society (1999 and 2002, respectively). She was elected to the National Academy of Sciences in 2004 and is a recipient of the National Academy of Sciences Award in Chemical Sciences and the National Medal of Science (both in 2009).

Dr. Czernin: You have published more than 500 papers, and I took the liberty to select 2 major contributions for our discussion. The first is, of course, the creation of ${ }^{18} F-F D G$, which has changed medicine, oncology, neurology, cardiology, and also inflammatory and infectious disease management. The second is your work on understanding addiction. What is interesting about these 2 major research areas is that you started to work on these at almost the same time. Is that correct?

Dr. Fowler: Yes. I joined Al Wolf's group at Brookhaven in 1971. He was just starting to look at the organic chemistry of ${ }^{11} \mathrm{C}$. So the first thing I worked on was the labeling of dopamine with ${ }^{11} \mathrm{C}$. As I recall, we were interested in imaging adrenal gland function. At that

COPYRIGHT @ 2019 by the Society of Nuclear Medicine and Molecular Imaging. time a lot of groups were looking at adrenal imaging agents, but I was also interested early on in brain tracers, especially for looking at dopamine receptors.

Dr. Czernin: How did your interest in brain function actually arise? This is somewhat unusual for a chemist.

Dr. Fowler: I always liked medicine and enjoyed reading medical journals, even though I'm a chemist. I was fascinated with how chemical compounds interact with living systems. When our

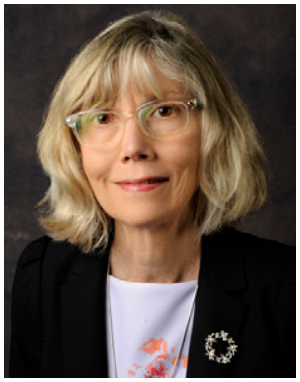

Joanna S. Fowler, PhD group started to work with Lou Sokoloff, Martin Reivich, and David Kuhl for developing 2- ${ }^{18}$ FDG I got interested in sugar metabolism of the brain and how you can modify a sugar molecule to have it trapped in cells. This was the basis of developing FDG.

So I just read a lot of literature, which helped enormously, because before we even started there was already so much known about how you could modify these molecules. So the design of the molecule was done just by looking at some old literature from the 1950s. Then we just had to figure out how to modify it synthetically with the radioisotopes and other tools we had at that time, which were kind of modest compared with what we have now.

Dr. Czernin: So the key people for FDG, in addition to you, were Wolf and Reivich?

Dr. Fowler: Louis Sokoloff, Martin Reivich, and their colleagues had developed an autoradiographic method for measuring brain glucose metabolism in animals using ${ }^{14} \mathrm{C}$-2-deoxyglucose as a tracer. And they and David Kuhl and Abass Alavi contacted Al Wolf to discuss the possibility of translating this autoradiographic method in animals to humans using in vivo imaging. Al had the reputation for knowing how to do chemistry with short-lived isotopes. We did not have a camera at Brookhaven, so we used David Kuhl's single-photon camera in Philadelphia. We were working against time to be able to do a synthesis that gave us enough of an ${ }^{18} \mathrm{~F}$-labeled deoxyglucose to get it from Brookhaven to the University of Pennsylvania.

We collaborated extensively with the University of Pennsylvania and NIH. They were doing somatosensory stimulation studies, among others. Similar studies were at the University of California Los Angeles with a dedicated PET scanner. One key chemist was our Japanese postdoc, Tatsuo Ido from Tohoku University (Japan), who optimized the production of ${ }^{18} \mathrm{~F}$ and the synthesis of FDG. Tatsuo was a major player.

Dr. Czernin: The first paper on FDG in oncology by Som et al. also came from Brookhaven. She showed that there was an early and high uptake of ${ }^{18} \mathrm{~F}-\mathrm{FDG}$ in a variety of transplanted and spontaneous mouse and rat tumors.

Dr. Fowler: Yes, that was Prantika Som. 
Dr. Czernin: When you think back to that time did you foresee the incredible success of FDG and PET imaging in general? Was it obvious?

Dr. Fowler: We were really focused on the brain at that point. But, yes, I was pretty excited about it. One of the key things about FDG and cancer is the very favorable target-to-background characteristics. You don't see that in many tracers. If you do a wholebody FDG scan you see the brain, heart, bladder, and tumors, but the rest of it is pretty blank, so that the signal-to-noise level for tumor detection is very high. Abbas Alavi, when we did the first studies, had the foresight to put a volunteer through a rectilinear scanner and got that beautiful picture of the distribution of ${ }^{18} \mathrm{~F}$ FDG in a healthy volunteer, showing the brain, heart, and bladder.

One of the things that really fascinated me about FDG was the design and how the biochemistry of the molecule is reflected in the image. You take that hydroxyl group on carbon-2 on the glucose molecule and replace it with a hydrogen or a fluorine atom. Then it can still undergo the first step in glucose metabolism, as well as facilitate transport into the brain, because you don't require that hydroxyl group. However, it doesn't get reabsorbed from the kidney, because you need the hydroxyl group in position 2 for active transport. So, glucose normally doesn't get excreted and gets reabsorbed in healthy individuals. It is observing beautiful biochemistry and predicting how this is going to behave in a complex living system that fascinated me.

Dr. Czernin: At about the same time you started working on MAO. Was that part of the general research program at Brookhaven or did you initiate that? the first thing she wanted to know. We labeled cocaine and had a paper on that, which gave us some important insights on drug kinetics and how kinetics affect the drug's reinforcing properties. At the same time we had FDG for looking at metabolism in the cocaine abuser. We had been looking at dopamine receptors in schizophrenia, so we had a little group of imaging probes that we could use to study the brain of individuals addicted to cocaine and other substances.

Dr. Czernin: What impact on understanding addiction came from these imaging approaches?

Dr. Fowler: The prevailing thought about addiction is that it is a moral weakness or a lack of willpower. But with imaging you can show real changes directly in the brain in addicted people. You can show that they have lower dopamine receptors. You can show that they have a lower metabolism in the orbital frontal cortex, which is the self-control center of the brain. So, imaging proved that there are real changes and that there is lower dopamine receptor density in other kinds of disorders in which people lose control of their behaviors, such as in obesity and all kinds of addictions. No matter which of these disorders we looked at there were lower dopamine receptors, like in the drug abusers. You then could ask whether this makes people more vulnerable to taking the drug. Or was it a secondary drug effect? Some of these questions have been answered in animal studies, where you could do a baseline study in animals, for example, and then study the long-term consequences of cocaine use.

Dr. Czernin: Do you think that the portfolio of imaging probes that you have could help in looking at drug effects directly or be

\section{"Progress in our field is made by attracting people from all over the world and providing opportunities to do work in a safe and stable environment. What will the workforce of the future look like if we exclude scientists from other countries or if we make them feel unwelcome?"}

Dr. Fowler: We had DOE support for basic chemistry and started to understand how chemical structures influence the distribution of chemical compounds in the whole body. We were interested in amines, which could easily be labeled with ${ }^{11} \mathrm{C}$. We started with some straight-chain amines and would make the chains longer and longer to test how this changed organ distribution. We were interested not only in making compounds but also in understanding how the structures of the compounds influence their distribution. So when we were making these amines we realized that they were broken down very rapidly by MAO. We got very interested in MAO, because it's such an important molecule in terms of drug development and in metabolizing many biogenic amines.

Dr. Czernin: When did it dawn on you that there is a very important group of diseases that could be better understood with imaging probes such as dopamine analogs?

Dr. Fowler: Interest in addiction came when Nora Volkow joined Brookhaven. She had been working at the University of Texas and had been imaging cocaine abusers with just ${ }^{15} \mathrm{O}$-water for blood flow. She observed large strokelike areas in the brains of the cocaine abusers. That led to the question of what it was about a drug like cocaine that makes it so powerfully addictive that people take it and can't stop. Essentially they have no control over it. She wanted to know more about where cocaine goes in the brain. How long does it stay? Does this have any bearing on the high from cocaine or why people take it in a bingelike pattern? So that was used as biomarkers for drug response? Would you be able to better develop antiaddiction drugs by using PET imaging probes, for example?

Dr. Fowler: Oh yes. One of the things that we became very interested in is using PET to look at drug dosing. For example, if you wanted something to block a receptor you would have a tracer for the receptor and treat at different doses of the drug to see how long the target is inhibited. So the more different probes of different receptors, transporters, and enzymes you have, the more likely it is that you can design studies to more effectively assess drug pharmacokinetics and pharmacodynamics.

Dr. Czernin: What is your view of the current drug addiction crisis? How would you address this best or what do you think is the best remedy?

Dr. Fowler: For the opiates there are replacement therapies, like methadone and suboxone, and they call these medicationassisted treatments. So if you can get someone into treatment and invest in treatment instead of investing in incarceration, there are drugs that can help. These replacement therapies have to be disseminated. Physicians must be aware that they cannot just prescribe huge numbers of these pain pills and should use alternatives for pain management in many cases. The design of new nonaddictive drugs for pain would also be important. Addiction often starts innocently, when a person visiting a physician gets a prescription for opiates, say for a toothache or something that could 
be treated with other analgesics. But then it develops into such a complicated insidious disease. Moreover, drug companies often do not go after addiction treatments because it's a stigma. They may feel that developing treatments for a group of people that society doesn't value very much is not good business. For example, not many drugs are being developed against nicotine addiction, which is a major public health problem. Many more are developed against the consequences of addiction, such as heart disease and some cancers. One invests in those diseases, but many really start with addiction, a disease of the brain.

Dr. Czernin: You are a member of the National Academy of Sciences, and you also received the National Medal of Science from President Obama. When you look back at your achievements what is your most important contribution?

Dr. Fowler: The initial designing of FDG, which really was done with collaborators at $\mathrm{NIH}$, the University of Pennsylvania, and my collaborators at Brookhaven, Al Wolf and Tatsuo Ido. The other contribution with Nora Volkow is the use of PET and labeled cocaine to measure cocaine uptake and clearance, showing its relationship to the drug high and bingelike patterns of use. Another one was showing that MAO activity was low in cigarette smokers. That was kind of a surprise and really interesting - this may in part explain why the rate of smoking is so high in depression and in psychiatric illnesses where smokers may be self medicating.

Dr. Czernin: What additional thoughts would you like to share with our readers?

Dr. Fowler: One thought I like to emphasize is the importance of attracting the brightest and best scientists to our fields--and to somehow come up with stable support and opportunities to create new knowledge. I am really worried about current prejudice against immigrants. Because if you look at how progress is made in our field, it's made by attracting people from all over the world and providing opportunities to do interesting work in a safe and stable environment. That's something that we can't forget. You know that science is our national treasure. We can't stop investing in science, and we can't stop welcoming scientists from other countries. I am worried about the recent discrimination against Chinese-American scientists. I worry a lot about this. This transcends a lot of the basic problems of tracer development. What will the workforce of the future be if we exclude scientists from other countries or if we make them feel unwelcome?

Dr. Czernin: Thank you, Dr. Fowler, for taking the time to talk with me and our readers. 